\title{
Hydrogen storage in amine boranes: Ionic liquid supported thermal dehydrogenation of ethylene diamine bisborane
}

\author{
Sebastian Sahler, Hannelore Konnerth, Nicole Knoblauch, Martin H.G. Prechtl ${ }^{*}$ \\ Institute of Inorganic Chemistry, University of Cologne, Greinstr. 6, 50939 Köln, Germany
}

\section{A R T I C L E I N F O}

\section{Article history:}

Received 24 September 2012

Received in revised form

20 December 2012

Accepted 27 December 2012

Available online 4 February 2013

Keywords:

Hydrogen storage

Ethylene diamine bisborane

Ammonia borane

Ionic liquids

Dehydrogenation

Polarity

\begin{abstract}
A B S T R A C T
A variety of ionic liquids has been tested for its catalytic effect on the dehydrogenation of ethylene diamine bisborane (EDB). The catalytic activity of ionic liquids, such as 1-butyl2,3-dimethylimidazolium chloride ([BMMIM]Cl), 1-butyl-2,3-dimethylimidazolium acetate ([BMMIM][OAc]), 1-butyl-3-methylimidazolium acetate ([BMIM][OAc]) and 1-butyl-3methylimidazolium methylsulfonate ([BMIM][OMs]) is compared and the mixture [BMMIM]Cl/EDB was investigated. This system is able to deliver about $6.5 \mathrm{wt} \%$ of hydrogen at $140{ }^{\circ} \mathrm{C}$ competing with conventional hydrogen storage pressure tanks. The correlation between polarity of the ILs and hydrogen yield was investigated and the suitability for hydrogen storage systems is evaluated and discussed.

Copyright @ 2013, Hydrogen Energy Publications, LLC. Published by Elsevier Ltd. All rights
\end{abstract} reserved.

\section{Introduction}

The ongoing demand for fossil fuels challenges current scientists to develop a material able to substitute oil based energy carriers sustainably. A very appealing material due to its wide availability and high energy content is hydrogen $[1,2]$. One critical hurdle in the application of hydrogen as energy carrier is its storage due to its low gravimetric density and scarce compressibility. One approach to solve this problem is storing hydrogen chemically and releasing it thermally or by reaction on demand [1-7].

As hydrogen storage material several compounds are discussed. Apart from (metal-)hydrides, amides and imides, the dehydrogenation and reforming of hydrocarbons and amine borane adducts is considered [2]. The advantages and disadvantages of these compounds and some physical or combined storage methods are precisely discussed in the review article by Schüth and co-workers [2].

The focus of research in the class of amine boranes lies mainly on ammonia borane $(A B)$ due to its low molecular weight and thus high hydrogen content [3,8-16]. The decomposition of $A B$ results in a distinct contamination of the released hydrogen by ammonia and borazine, which is a major problem for application in fuel cells $[13,17,18]$. The decomposition of $\mathrm{AB}$ derivatives can circumvent this problem since nitrogen substituted derivatives of borazine as well as substituted amines are substantially less volatile. In this context methyl amine borane (MeAB) [19], sec-butyl amine

\footnotetext{
* Corresponding author. Tel.: +49 221470 1981; fax: +49 2214701788.

E-mail address: martin.prechtl@uni-koeln.de (M.H.G. Prechtl).

URL: http://catalysis.uni-koeln.de/
}

0360-3199/\$ - see front matter Copyright @ 2013, Hydrogen Energy Publications, LLC. Published by Elsevier Ltd. All rights reserved. http://dx.doi.org/10.1016/j.ijhydene.2012.12.150 
borane (SBAB) [20], hydrazine borane (HB) [7] and ethylene diamine bisborane (EDB) have been investigated $[5,6]$.

For engineering and handling reasons liquid hydrogen storage materials are preferred. Especially controllability of the release and refueling issues favor a liquid storage system over solid ones.

One approach toward a liquid system and to improve gas purity is to incorporate an amine borane in a cyclic compound. The cyclic boron nitrogen (BN) system BN-2-methylcylopentane is able to release $4.7 \mathrm{wt} \%$ of hydrogen and has the major advantage of being liquid [21]. The dehydrogenation product of this compound is the cyclic trimer, which is also liquid. The recycling of this system was demonstrated, although its efficiency is still unsatisfactory.

Besides the approaches of using molecular hydrocarbons as hydrogen storage material, the application of ionic liquids (IL) and their unique properties promise considerable advantages. ILs support the hydrogen liberation [11] and uptake may be enhanced by providing a liquid system when solubilizing solid spent fuel materials. ILs have a very low volatility, hence no contamination of the gas stream is to be expected, and appear chemically inert while providing a polar solvent environment for chemical reactions. Their tunable properties make them interesting for a variety of applications in this field of research [22].

The application of ILs as hydrogen storage material has been attempted in two different ways. The first was the incorporation of a cyclohexyl moiety in an imidazolium IL, so that the cation of the IL can be reversibly dehydrogenated [23]. The second approach targeted a BN compound, but ionic in nature: The salt consisting of methylguanidinium as cation and borohydride as anion is liquid at room temperature and depicts an interesting material for hydrogen liberation [24]. Due to the formation of polymeric species the dehydrogenation results in a solid spent fuel product.

In another way ILs can be employed to solubilize a storage material. This approach was investigated in the blend of SBAB and $\mathrm{AB}$ in the IL ethylmethylimidazolium ethylsulfate ([EMIM] $\left[\mathrm{EtSO}_{4}\right]$ ) by Baker and co-workers [20]. This liquid blend is able to release hydrogen in high purity, since the liberation of ammonia and borazine is prevented. One of the major drawbacks, which is a typical problem for application of ILs in this context, is the reduced gravimetric efficiency resulting from the addition of IL to the system.

The gravimetric efficiency is a major advantage of several solid systems. One solid $A B$ derivative under investigation is $\mathrm{HB}$ mixed with $\mathrm{LiH}$ to balance the number of protic and hydridic hydrogen atoms in the system [7]. The gravimetric efficiency of this system is outstanding; nearly $12 \mathrm{wt} \%$ could be released at moderate temperatures.

In the mixture of $A B$ and 1-butyl-3-methylimidazolium chloride ([BMIM]Cl) [11] the use of the IL clearly lowers the temperature required for dehydrogenation and improves the extent of hydrogen production. It is proposed that this enhancement is caused by the stabilizing effect of the IL in the formation of an intermediate diammoniate of diborane.

The influence of transition metal salts on this system was investigated [25]. At low temperatures these metal salts improve hydrogen yield from $A B$ decomposition in [BMIM]Cl considerably. Under the mentioned conditions the reduction of these metal salts seems plausible. Although the nature of the active species remains unclear, the beneficial effect of some metal salts could be demonstrated.

Efficient recycling is a major topic in the search for a hydrogen storage material since recycling is crucial for an acceptable efficiency. One prototypic reaction for the regeneration of $A B$ spent fuel has recently been demonstrated by Sutton and co-workers [26]. The regeneration was realized by stoichiometric reduction with hydrazine in liquid ammonia.

In our approach different ILs have been tested for supported dehydrogenation of EDB. The polar reaction medium provided by some ILs enhances decomposition in means of reduced temperature and extent of hydrogen release. For one particular IL, namely 1-butyl-2,3-dimethylimidazolium chloride ([BMMIM]Cl) the dehydrogenation characteristics for different compositions and temperatures have been tested and compared. The thermal dehydrogenation can be supported by certain ILs in regards to the required temperature and overall yield at temperatures of $100-140^{\circ} \mathrm{C}$.

\section{Experimental}

All ILs have been prepared according to or adapted from literature methods [27-29]. All dehydrogenation reactions were carried out without precautions against moisture or oxygen. For the dehydrogenation experiments, in general $25 \mathrm{mg}$ EDB was mixed with $25 \mathrm{mg}$ of the respective IL. In cases of liquid ILs a tolerance of $10 \%$ was set due to technical limitations. A glass reactor was connected to a mass flow meter (vide infra) and set into an aluminum block that was preheated to the desired temperature. All dehydrogenation data were corrected by experimental data of empty glass reactors at the set temperature to compensate for thermal expansion.

The amount of released hydrogen was determined with a mass flow meter of the manufacturer mks connected via an analog connection to a desktop computer. The data were recorded with the software RealView 3.0 by ABACOM. Data processing was conducted with OriginPro $8.5 \mathrm{G}$ by OriginLab. The purity of the released hydrogen was controlled in representative samples with a HPR20 gas analyzing system by Hiden Analytical.

\section{Results and discussion}

\subsection{Screening of ILs}

The enhanced effect of certain ILs on the thermal $\mathrm{H}_{2}$ liberation from EDB has been evaluated. The thermal dehydrogenation can be described as a dehydropolymerization as shown in the following reaction scheme (Fig. 1). The single molecules of EDB oligomerize to boron bridged species while releasing hydrogen.

For this application a variety of ILs has been chosen. The first subset are ionic liquids containing methyl and dimethylimidazolium cations (see Fig. 2). Derivatives with butyl chains, butyronitrile sidechains (1-(butyronitrile)-3methylimidazolium chloride) and diethylamino functionalized ethyl sidechains (1-(N,N-diethyl-2-amino)ethylene-2,3dimethylimidazolium chloride) were applied. As counter 


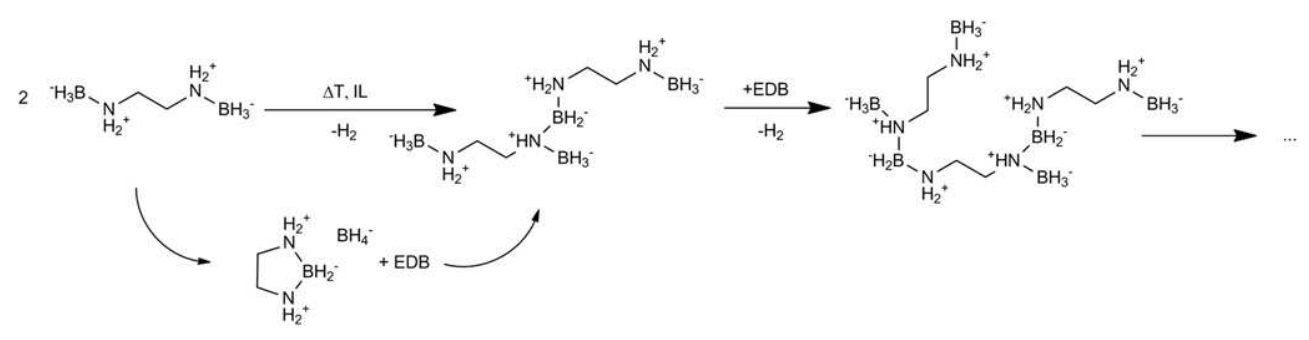

Fig. 1 - Scheme of the dehydropolymerization of EDB.

ions methylsulfonate (mesylate), N,N-bis-(trifluorosulfonyl) imide, chloride, acetate, iodide, tetrafluoroborate and hexafluorophosphate were used. The possible enhancing effect of these ILs on the dehydrogenation of EDB/IL mixtures was investigated.

It should be noted that the decomposition of pure EDB has an induction period, that is suppressed by almost every tested IL, apart from [BMMIM] $\left[\mathrm{NTf}_{2}\right]$ and [BMIM][OMs] (see Fig. 3). The least performing IL in this subset is [BMMIM]I. Although the induction period is shorter, the system shows a lower yield than the pure EDB system. The ILs [BMMIM] $\left[\mathrm{NTf}_{2}\right],[(\mathrm{CN}) \mathrm{BMIM}] \mathrm{Cl}$ and $\left[\mathrm{BMMIM}^{\mathrm{B}}\left[\mathrm{PF}_{6}\right]\right.$ perform very similar to pure $\mathrm{EDB}$ in reaction rate and yield. A slight enhancement is obtained by using [BMIM][OMs], [BMMIM] $\left[\mathrm{BF}_{4}\right]$ and a stronger effect by [BMMIM]Cl and [(Et $\left.)_{2} \mathrm{NEMMIM}\right] \mathrm{Cl}$. The latter increase the yield of $\mathrm{H}_{2}$ by about $50 \%$. The best performing ILs tested here are the acetate ILs [BMIM][OAc] and [BMMIM][OAc], resulting in higher reaction rates and improved yields up to $80-90 \%$.

Most of the dehydrogenations at $120{ }^{\circ} \mathrm{C}$ occur in about $20 \mathrm{~min}$. The reaction characteristically starts fast and slows down during progress. In the cases of [BMMIM][OAc] and
[BMIM][OAc] the reaction takes about $40 \mathrm{~min}$, though the release is faster than all other tested ILs (see Fig. 3).

To compare the yield of dehydrogenation reactions with different EDB/IL mixtures, the yields are depicted without kinetic information in Fig. 4. The application of [BMMIM]I, [BMMIM] $\left[\mathrm{NTf}_{2}\right.$ ], [BMMIM][PF 6$]$, [(CN)BMIM]Cl, [BMIM][OMs] and [BMMIM] $\left[\mathrm{BF}_{4}\right]$ result in hydrogen yields similar to the dehydrogenation of neat EDB. Higher yields are obtained when using [BMMIM]Cl, [(Et) $\left.{ }_{2} \mathrm{NEMMIM}\right] \mathrm{Cl}$, [BMMIM] $\mathrm{BAc}$ ) or [BMIM] [OAc]. These ILs yield 3.02, 3.31, 3.67 and 3.81 equivalents of hydrogen from EDB respectively in comparison to 2.14 equivalents from pure EDB decomposition.

Contradicting our initial expectations the introduction of functional groups on the sidechains of the ILs does not result in significantly higher yields ([(CN)BMIM]Cl and [(Et $\left.)_{2} \mathrm{NEMMIM}\right]$ $\mathrm{Cl})$. The amine functionalized IL performs slightly better (3.31 eq.) in comparison to the analog IL with a butyl-sidechain (3.02 eq.), the nitrile functionalized IL (2.20 eq.) performs equally as neat EDB (2.14 eq.), hence no significant beneficial effect on the dehydrogenation is observable.

The subset of ILs with [BMMIM] cations follows a certain trend implied by the anion. According to the trend in mean<smiles></smiles>

1-Butyl-3-methylimidazolium mesylate

[BMIM][OMs]<smiles></smiles>

1-Butyl-3-methyl-imidazoliumacetate [BMIM][OAc]<smiles></smiles>

1-Butyl-2,3-dimethylimidazolium-N,N-bis(trifluorosulfonyl)imide [BMMIM][NTf ${ }_{2}$ ]

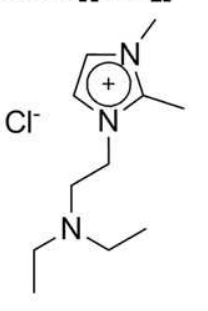

1-(N,N-Diethyl-2-amino)ethylen-2,3-dimethylimidazoliumchloride<smiles>Cn1cc[n+](CCCC#N)c1</smiles>

1-(3-butyronitrile)-3methyl-imidazoliumchloride [(CN)BMIM]CI<smiles></smiles>

1-Butyl-2,3-dimethylimidazolium [BMMIM]X

[(Et) $\left.{ }_{2} \mathrm{NEMMIM}\right] \mathrm{Cl}$

Fig. 2 - Structures of applied ionic liquids with an imidazolium cation. 


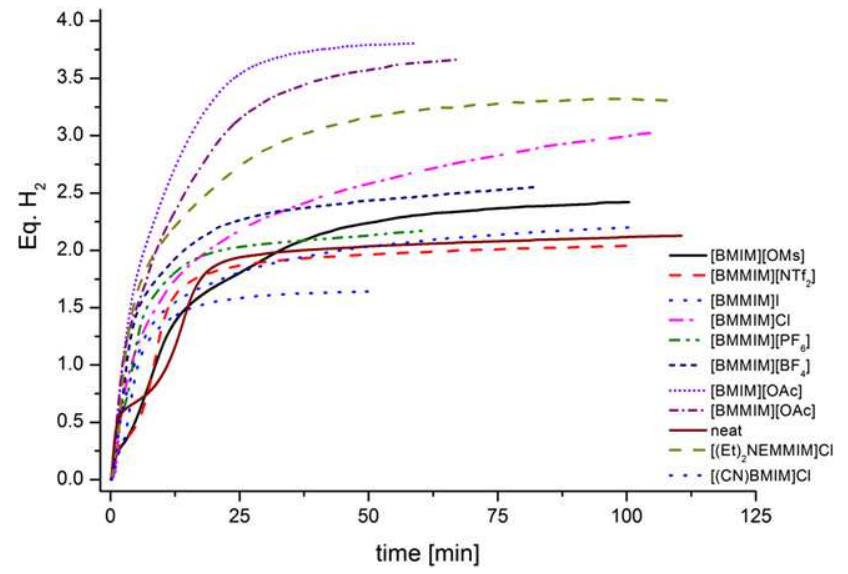

Fig. 3 - Time-resolved hydrogen release of neat EDB and different EDB/IL mixtures at $120{ }^{\circ} \mathrm{C}$.

$\beta$-values of the Kamlet-Taft parameters reported by Jessop et al. [30] the yields of hydrogen relate to the basicity of the ILs. The ILs containing anions with very low mean $\beta$-values, i.e. $\left[\mathrm{NTf}_{2}\right]^{-}\left[\mathrm{PF}_{6}\right]^{-}$and $\left[\mathrm{BF}_{4}\right]^{-}$as well as the ILs containing anions with higher mean $\beta$-values like $\mathrm{Cl}^{-}$and $[\mathrm{OAc}]^{-}$ bearing the identical cationic species $\left([\mathrm{BMMIM}]^{+}\right)$strictly follow the trend as can be seen in Fig. 5. There seems to be a distinct tendency that correlates basicity and hydrogen yield in this setup though there certainly is no strict linear correlation.

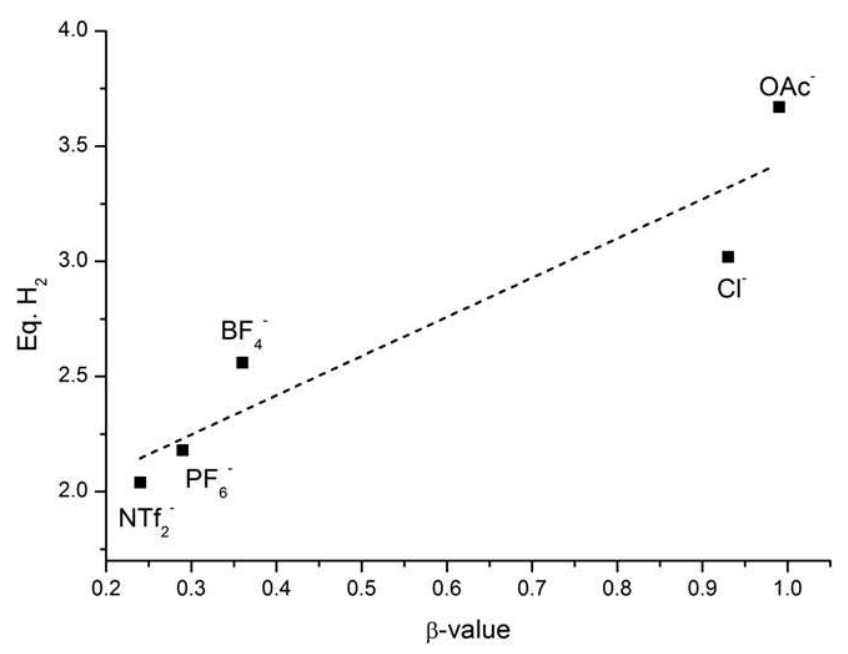

Fig. 5 - Plot of equivalents of released hydrogen in relation to mean $\beta$-values of anions of the applied IL (for $\mathrm{NTf}_{2}^{-}, \mathrm{PF}_{6}^{-}$, $\mathrm{BF}_{4}^{-}, \mathrm{Cl}^{-}$and $\mathrm{OAc}^{-}$) (line for visualization only).

As there is no mean $\beta$-value reported for the iodide anion, it is omitted. While the ILs containing anions with lower $\beta$-values result in hydrogen yields similar to neat EDB dehydrogenation, the more basic ones (higher mean $\beta$-values, $\mathrm{Cl}^{-}$and $[\mathrm{OAc}]^{-}$) significantly increase hydrogen yield.

The observed correlation between basicity and promoting effect on dehydrogenation can as well be found in the results

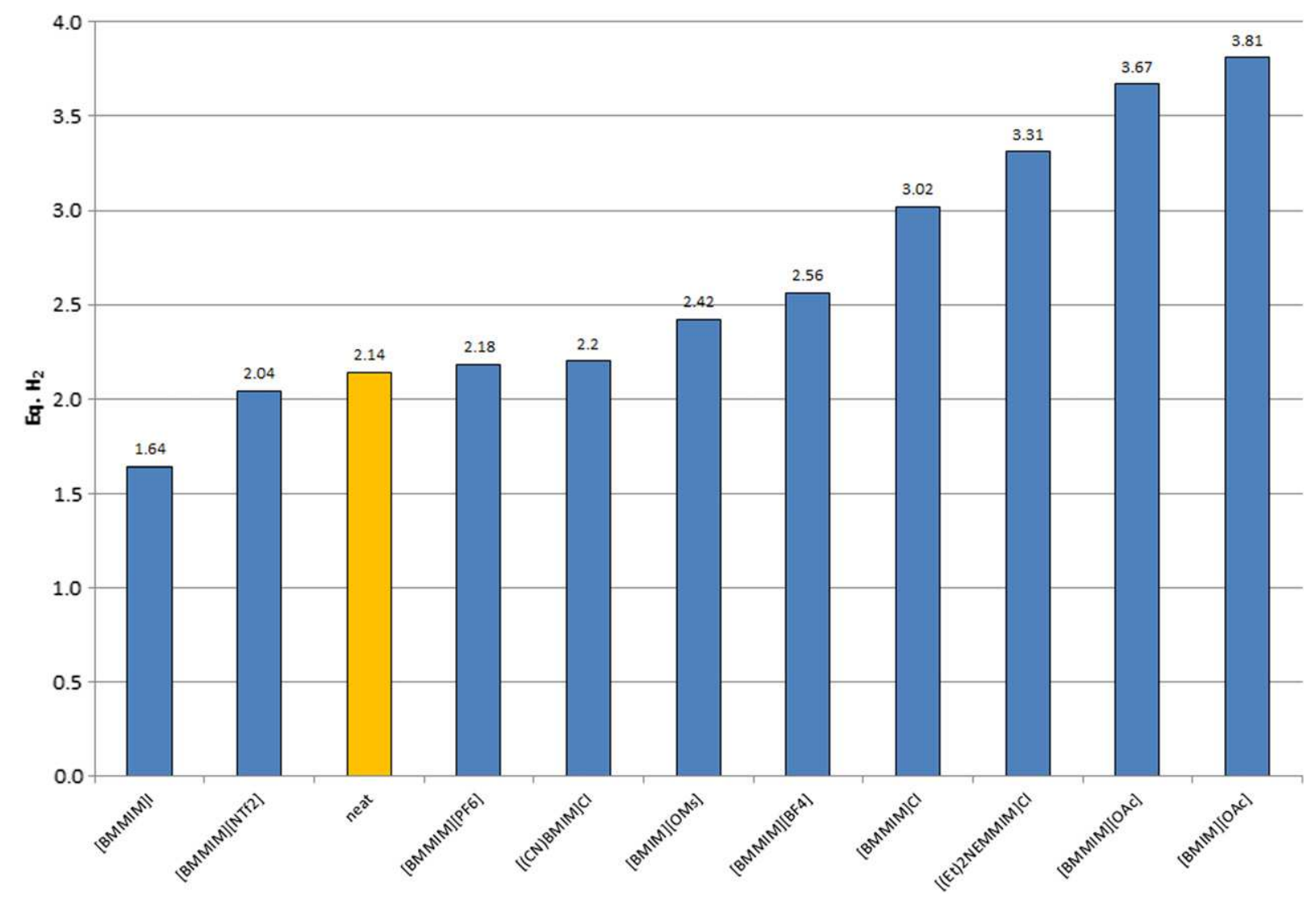

Fig. 4 - Dehydrogenation yields of EDB supported by imidazolium based ILs. 
Table 1 - Dehydrogenation experiments of EDB toward the effect of basicity of acetate anions at $120^{\circ} \mathrm{C}$.

\begin{tabular}{llc} 
Entry & \multicolumn{1}{c}{ Composition } & Eq. $\mathrm{H}_{2}$ \\
\hline 1 & EDB & 2.14 \\
2 & EDB + Na[OAc] & 2.20 \\
3 & EDB $+[$ [BMMIM]Cl & 3.02 \\
4 & EDB $+[$ BMMIM][OAc] & 3.67 \\
5 & EDB $+[$ BMMIM]Cl + Na[OAc] & 2.72 \\
\hline
\end{tabular}

obtained by Sneddon et al. [11] for the dehydrogenation of AB. In their experiments with different imidazolium ILs, the hydrogen yield follows the same basicity trend as in our experiments. Though they varied the cations sidechains the yield seems to be determined by the anion and the successive basicity. The dehydrogenations of EDB as well as AB proceed via an ionic intermediate as shown in Fig. $1[5,11]$. The formation of the intermediate is proposed to be the rate determining step. The increase in reaction rate as well as lowering of the required temperature may result from the stabilization of this ionic intermediate by a more Brønsted basic environment as provided by certain ILs.

To verify the effect of the ILs and distinguish promoting effects of the ILs from basicity effects of the acetate anion we repeated the dehydrogenation experiment with the addition of sodium acetate.

In comparison to decomposition of pure EDB (Table 1, entry 1 ), the addition of sodium acetate (Table 1, entry 2) yields (within experimental error) a similar amount of hydrogen. The mixture of EDB with [BMMIM]Cl and sodium acetate (Table 1, entry 5) resulted in a lower yield compared to EDB with [BMMIM]Cl (Table 1, entry 3). The preformed IL [BMMIM] [OAc] appears crucial for improved hydrogen yield (Table 1, entry 4).

Besides the investigations toward imidazolium ILs a variety of pyrrolidinium and pyridinium ILs were examined for promoting effects on the dehydrogenation of EDB (see Fig. 6). In this subset four different ILs bearing a pyrrolidinium IL, two of which with butyl and methyl sidechains ([BMpyr][OMs] and [BMpyr]Cl) and the remaining two with a butyronitrile and a methyl sidechain ([(CN)BMpyr] $\left[\mathrm{NTf}_{2}\right]$ and [(CN)BMpyr] $\left.\left[\mathrm{N}(\mathrm{CN})_{2}\right]\right)$ were investigated. Secondly, two functionalized pyridinium ILs were subjected to studies, one bearing a butyronitrile sidechain $([(\mathrm{CN}) \mathrm{Bpy}] \mathrm{Cl})$, the other one with an $\mathrm{N}, \mathrm{N}$ Diethyl-2-aminoethyl sidechain ([(Et) $\left.\left.{ }_{2} \mathrm{NEpy}\right][\mathrm{OTs}]\right)$.

In the dehydrogenation experiments containing each one of these ILs in a mixture with EDB, all applied ILs suppress the induction period of neat EDB dehydrogenation (see Fig. 7). The nitrile functionalized pyridinium IL $[(\mathrm{CN}) \mathrm{Bpy}] \mathrm{Cl}$ reduces hydrogen yield drastically. All other tested pyrrolidinium and pyridinium ILs, namely [BMpyr][OMs], [(CN)BMpyr][ $\left.\mathrm{NTf}_{2}\right]$, [BMpyr]Cl, [(Et) $\left.{ }_{2} \mathrm{NEpy}\right][\mathrm{OTs}]$ and [(CN)BMpyr] $\left[\mathrm{N}(\mathrm{CN})_{2}\right]$, result in similar yields as well as similar dehydrogenation speeds. The best performance in this subset is observed with [(CN)BMpyr] [NTf $\mathrm{N}_{2}$, which yields 2.62 equivalents of hydrogen whereas 2.08 equivalents are obtained with [(Et) $\left.{ }_{2} \mathrm{NEpy}\right][\mathrm{OTs}]$. In contrast to the previously discussed imidazolium ILs the pyrrolidinium and pyridinium ILs have a distinctly smaller effect on the dehydrogenation of EDB.

In direct comparison of the two ILs with a [(CN)BMpyr $]^{+}$ cation a difference to the imidazolium ILs can be seen; here the less basic IL $\left(\left[\mathrm{NTf}_{2}\right]^{-}\right)$performs better than the more basic one $\left(\left[\mathrm{N}(\mathrm{CN})_{2}\right]^{-}\right)$. The same applies for the $[\mathrm{BMpyr}]^{+}$ILs: the more basic (higher $\beta$-value) $\mathrm{Cl}^{-}$IL performs worse than the $[\mathrm{OMs}]^{-}$IL. Interestingly the least performing of all chosen ILs is one containing a chloride anion, contrasting the results with the imidazolium ILs. It seems that as long as there is no imidazolium cation present, a different mechanism underlies the supporting effect.

It should be noted, that in case of the tested [OMs] $]^{-}$ILs as well as the $[\mathrm{OAc}]^{-}$ILs the yield is nearly the same (compare Figs. 4 and 8). Thus, the effect of the anion seems superior in<smiles>CCCC[N+]1(C)CCCC1</smiles>

1-Butyl-1-methylpyrrolidinium mesylate

[BMpyr][OMs]<smiles>CCCC[N+]1(C)CCCC1</smiles>

1-Butyl-1-methylpyrrolidinium chloride

[BMpyr]Cl<smiles>C[N+]1(CCCC#N)CCCC1</smiles>

1-(Butyronitrile)-1-methylpyrrolidinium N,N-bis(trifluorosulfonyl)imide [(CN)BMpyr][ NTf $\left._{2}\right]$<smiles>N#CCCC[n+]1ccccc1</smiles>

1-(Butyronitrile)pyridinium chloride [(CN)Bpy]Cl<smiles>N#C[N-]C#N</smiles>

1-(Butyronitrile)-1-methylpyrrolidinium dicyanamide

[(CN)BMpyr][N(CN $\left.)_{2}\right]$<smiles>CCN(CC)CC[n+]1ccccc1</smiles>

1-(N,N-Diethyl-2-amino)ethylenpyridinium tosylate

[(Et) ${ }_{2}$ NEtpy][OTs]

Fig. 6 - Structures of used ionic liquids with a pyrrolidinium or pyridinium cation. 


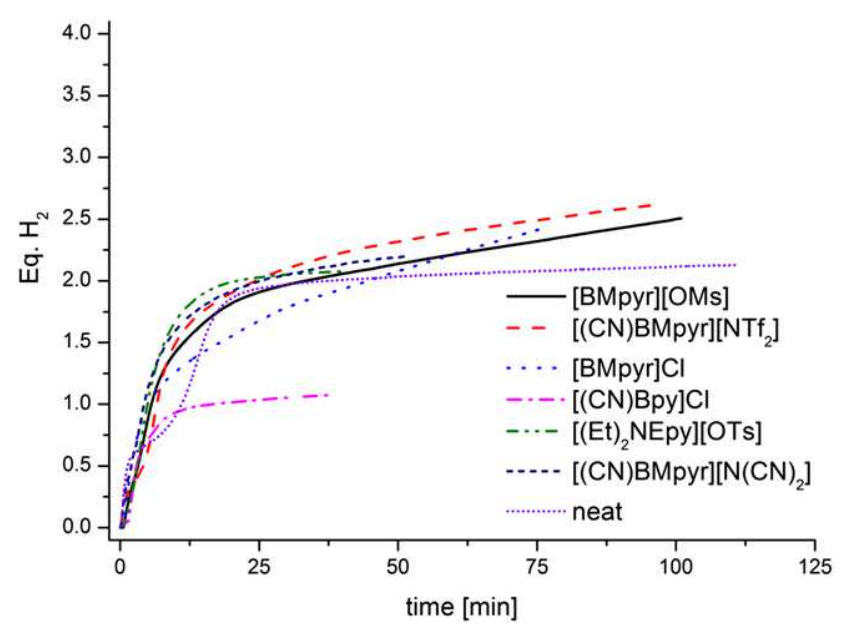

Fig. 7 - Time-resolved hydrogen release of neat EDB and different EDB/IL mixtures at $120{ }^{\circ} \mathrm{C}$.

these cases to the effect of the cation. As contrast in the case of the different tested $\mathrm{Cl}^{-}$ILs the variation in yield is enormous. Therefore, we conclude that the cation plays a crucial role in the case of the $\mathrm{Cl}^{-}$ILs.

To confirm the purity of the released hydrogen we investigated the evolved gas via mass spectrometry of representative samples, which has been applied before [4]. In case of the tested $[\mathrm{OAc}]^{-}$ILs $\mathrm{CO}_{2}$ and in all experiments diborane $\left(\mathrm{B}_{2} \mathrm{H}_{6}\right)$ and ammonia $\left(\mathrm{NH}_{3}\right)$ are possible co-products. No co-products, but solely air and hydrogen have been found in the dehydrogenation reaction of EDB in [BMIM] [OAc] (see Fig. 9). The outstanding gas purity of EDB decomposition remains unchanged by the addition of IL.

After initial experiments with a variety of ILs, [BMMIM]Cl was investigated in more detail. As accessibility is crucial [BMMIM]Cl was the IL of choice as a compromise between performance and access.

\subsection{Investigation of the $\mathrm{EDB} /[\mathrm{BMMIM}] \mathrm{Cl}$ system}

In further studies we varied the composition and dehydrogenation temperature of the $\mathrm{EDB} /[\mathrm{BMMIM}] \mathrm{Cl}$ system and

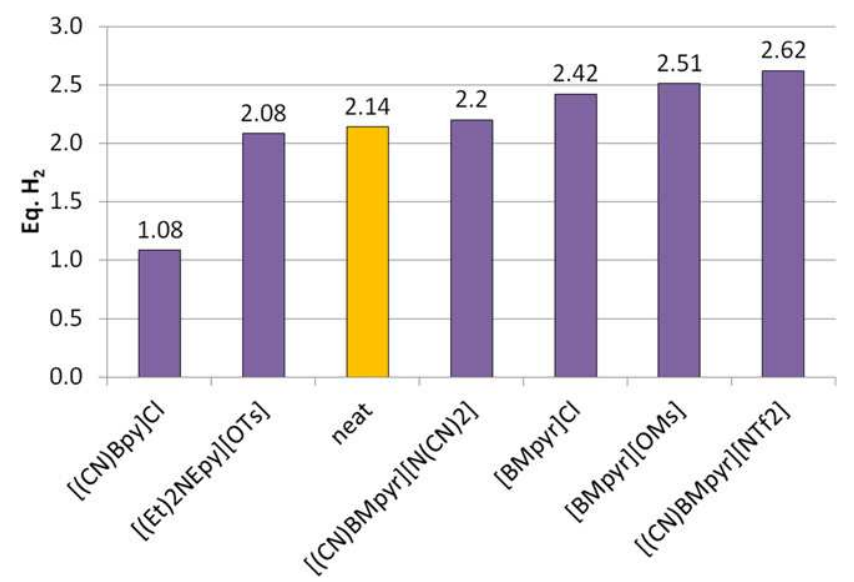

Fig. 8 - Dehydrogenation yields of EDB supported by pyrrolidinium or pyridinium based ILs.

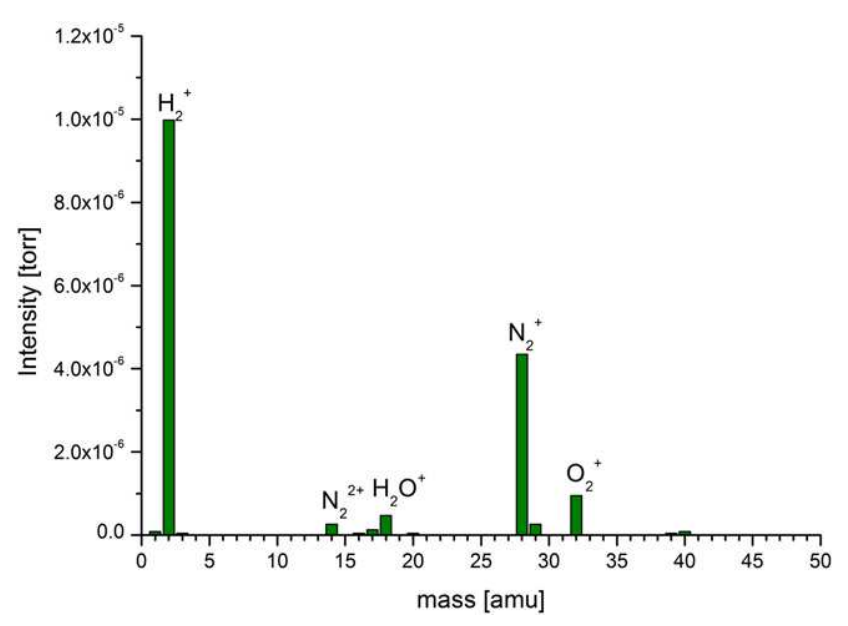

Fig. 9 - Mass spectrum of the released gas from the dehydrogenation of EDB/[BMIM][OAc].

investigated the same dehydrogenation reaction. Since weight efficiency is crucial for hydrogen storage systems we varied the amount of IL. As it would be advantageous for the system to operate at lower temperatures, we tested it at different temperatures. In Fig. 10 the results of variations in composition at $100^{\circ} \mathrm{C}, 120^{\circ} \mathrm{C}$ and $140^{\circ} \mathrm{C}$ are displayed.

The temperature influences the outcome of the dehydrogenation drastically. In general, higher temperatures increase the amount of released hydrogen. At $100^{\circ} \mathrm{C}$ the decomposition of neat EDB releases nearly no hydrogen, so the addition of a small amount of IL results in a large benefit for the reaction: the 0.25:1 mixture (IL:EDB) of [BMMIM]Cl and EDB delivers a maximum for the release of hydrogen of about $3.5 \mathrm{wt} \%$. Higher amounts of IL result in a loss of efficiency due to the weight penalty induced by the additional weight of the IL. The $120^{\circ} \mathrm{C}$ curve demonstrates this fact distinctly. Though additional IL results in a higher yield (compare Fig. 11) this cannot compensate for the weight penalty introduced by the IL. From

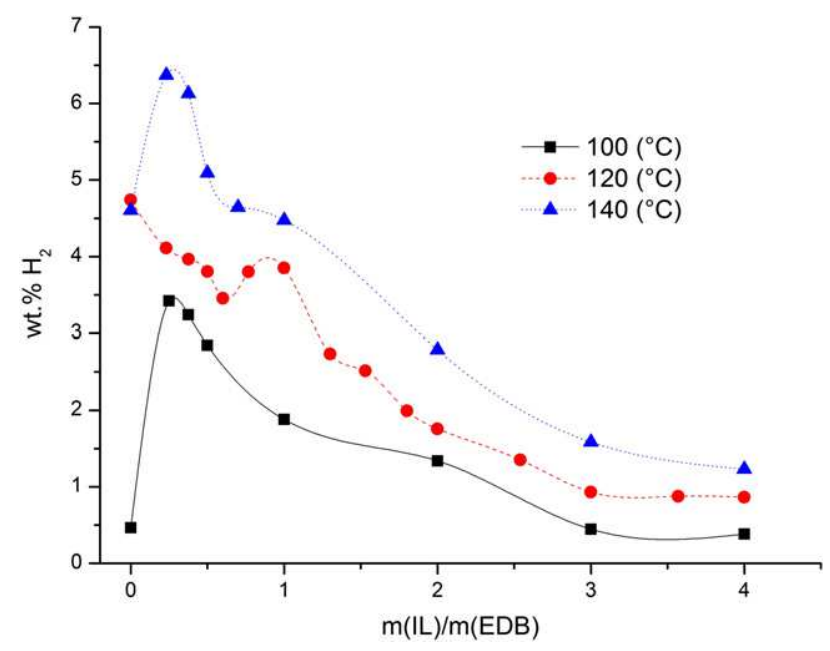

Fig. 10 - Efficiency curves of varied EDB/[BMMIM]Cl mixtures at different temperatures (lines for visualization only). 


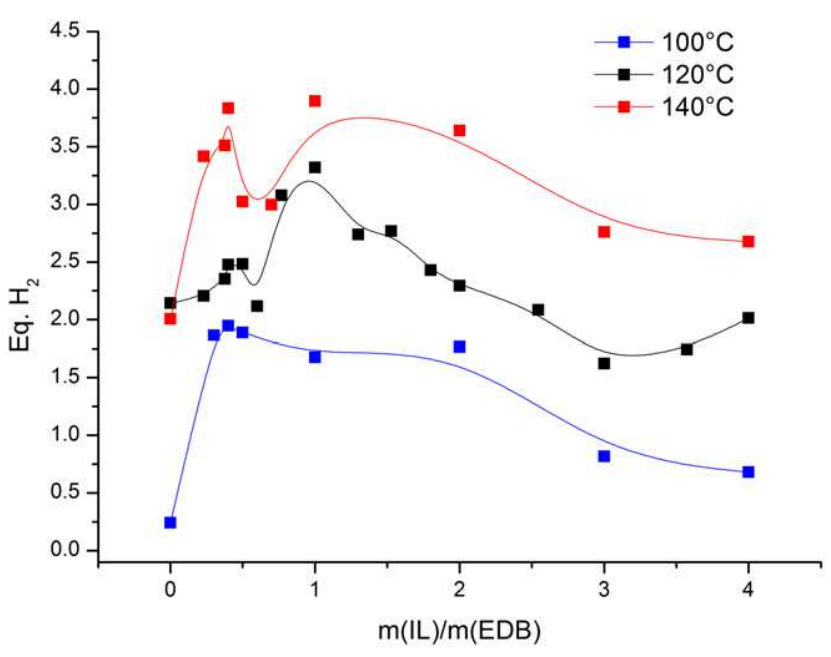

Fig. 11 - Dehydrogenation curves of different EDB/IL mixtures. (lines for visualization only.)

the weight-efficiency point of view at $120^{\circ} \mathrm{C}$ pure EDB is more efficient than all EDB/IL mixtures tested. This is not the case at $140{ }^{\circ} \mathrm{C}$. Here the catalytic effect of the IL results in such a gain in yield, that it overcompensates the penalty in weight and the efficiency curve passes a maximum at a ratio of 0.3:1 (IL:EDB) (6.5 wt\%). When the ratio is increased to $1: 1$ the catalytic effect of the IL precisely compensates for the weight penalty and the overall efficiency is equal to neat EDB decomposition.

The weight penalty is of crucial importance here, since the efficiency of hydrogen release in regards to the amount of EDB differs significantly from the weight efficiency values. For clarification the following plot (see Fig. 11) depicts the released hydrogen in chemical equivalents with respect to the active material i.e. EDB.

In view of efficiency and weight efficiency the addition of large amounts of IL is undesirable. Despite the slight increase in hydrogen yield the weight penalty bears a much stronger negative effect on efficiency. When only a small amount of IL is added to EDB, the dehydrogenation distinctly benefits in efficiency as well as weight efficiency. The effect is strongest at lower temperatures, as pure EDB scarcely releases hydrogen at temperatures of $100^{\circ} \mathrm{C}$. Here the addition of IL is most advantageous for the reaction.

\section{Conclusion}

The addition of certain ionic liquids to ethylene diamine bisborane is beneficial for promoting dehydrogenation reactions. Some ILs support the dehydrogenation strongly, though examples have been found that adversely affect the hydrogen yield. The performances of imidazolium ILs correlate with the polarity, where polar ILs bring a greater benefit to the reaction than unpolar ones. This effect is accounted to stabilization of the ionic intermediate suggested by Bowden, Autrey et al. [5]. As long as there is no imidazolium ion present, probably a different mechanism applies, where basicity does not reign the effect. The deeper investigation of the IL [BMMIM]Cl showed that mixtures of this IL with EDB are able to improve the hydrogen yield considerably in most compositions at temperatures between $100^{\circ} \mathrm{C}$ and $140^{\circ} \mathrm{C}$. The efficiency with respect to the systems weight can be improved by the addition of a small amount of IL, which improves the hydrogen yield overcompensating for the weight penalty introduced by the IL itself. Especially at lower temperatures the use of ILs is beneficial for the dehydrogenation meaning the required temperature for dehydrogenation is distinctly lowered.

\section{Acknowledgments}

We want to thank the Ministerium für Innovation, Wissenschaft und Forschung NRW (MIWF-NRW) for financial support within the Energy Research Program for the Scientist Returnee Award for M.H.G. Prechtl. S. Sahler wants to thank C. Gedig, L. Heim and M. Keßler for providing ionic liquids, M. Keßler and T. Leuning for helpful discussion.

\section{R E F E R E N C E S}

[1] Schlapbach L, Zuttel A. Hydrogen-storage materials for mobile applications. Nature 2001;414:353-8.

[2] Eberle U, Felderhoff M, Schuth F. Chemical and physical solutions for hydrogen storage. Angew Chem Int Ed Engl 2009;48:6608-30.

[3] Staubitz A, Robertson APM, Manners I. Ammonia-borane and related compounds as dihydrogen sources. Chem Rev 2010; 110:4079-124.

[4] Scholten JD, Prechtl MHG, Dupont J. Decomposition of formic acid catalyzed by a phosphine-free ruthenium complex in a task-specific ionic liquid. Chemcatchem 2010;2:1265-70.

[5] Neiner D, Karkamkar A, Bowden M, Joon Choi Y, Luedtke A, Holladay J, et al. Kinetic and thermodynamic investigation of hydrogen release from ethane 1,2-di-amineborane. Energy Environ Sci 2011;4:4187-93.

[6] Groshens TJ, Hollins RA. New chemical hydrogen storage materials exploiting the self-sustaining thermal decomposition of guanidinium borohydride. Chem Commun 2009:3089-91.

[7] Hugle T, Kuhnel MF, Lentz D. Hydrazine borane: a promising hydrogen storage material. J Am Chem Soc 2009;131:7444-6.

[8] Hwang HT, Al-Kukhun A, Varma A. High and rapid hydrogen release from thermolysis of ammonia borane near PEM fuel cell operating temperatures. Int J Hydrogen Energy 2012;37: 2407-11.

[9] Basu S, Zheng Y, Gore JP. An experimental study of neat and ionic liquid-aided ammonia borane thermolysis. J Power Sources 2011;196:734-40.

[10] Ahluwalia RK, Peng JK, Hua TQ. Hydrogen release from ammonia borane dissolved in an ionic liquid. Int J Hydrogen Energy 2011;36:15689-97.

[11] Himmelberger DW, Alden LR, Bluhm ME, Sneddon LG. Ammonia borane hydrogen release in ionic liquids. Inorg Chem 2009;48:9883-9.

[12] Himmelberger DW, Yoon CW, Bluhm ME, Carroll PJ, Sneddon LG. Base-promoted ammonia borane hydrogenrelease. J Am Chem Soc 2009;131:14101-10.

[13] Stephens FH, Pons V, Baker RT. Ammonia-borane: the hydrogen source par excellence? Dalton Trans 2007:2613-26.

[14] Bluhm ME, Bradley MG, Butterick R, Kusari U, Sneddon LG. Amineborane-based chemical hydrogen storage: enhanced 
ammonia borane dehydrogenation in ionic liquids. J Am Chem Soc 2006;128:7748-9.

[15] Diwan M, Hwang HT, Al-Kukhun A, Varma A. Hydrogen generation from noncatalytic hydrothermolysis of ammonia borane for vehicle applications. AIChE J 2011;57:259-64.

[16] Swinnen S, Nguyen VS, Nguyen MT. Hydrogen release from ammonia borane and derivatives in the presence of a ruthenium complex incorporating cooperative PNP ligands. Chem Phys Lett 2011;513:195-200.

[17] Al-Kukhun A, Hwang HT, Varma A. A comparison of ammonia borane dehydrogenation methods for protonexchange-membrane fuel cell vehicles: hydrogen yield and ammonia formation and its removal. Ind Eng Chem Res 2011; 50:8824-35.

[18] Halseid R, Vie PJS, Tunold R. Effect of ammonia on the performance of polymer electrolyte membrane fuel cells. J Power Sources 2006;154:343-50.

[19] Jaska CA, Temple K, Lough AJ, Manners I. Transition metalcatalyzed formation of boron-nitrogen bonds: catalytic dehydrocoupling of amine-borane adducts to form aminoboranes and borazines. J Am Chem Soc 2003;125: 9424-34.

[20] Mal SS, Stephens FH, Baker RT. Transition metal catalysed dehydrogenation of amine-borane fuel blends. Chem Commun 2011;47:2922-4.

[21] Luo W, Campbell PG, Zakharov LN, Liu SY. A singlecomponent liquid-phase hydrogen storage material. J Am Chem Soc 2011;133:19326-9.

[22] Sahler S, Prechtl MHG. Advancement in molecular hydrogen storage systems. Chemcatchem 2011;3:1257-9.
[23] Stracke MP, Ebeling G, Cataluna R, Dupont J. Hydrogenstorage materials based on imidazolium ionic liquids. Energy Fuels 2007;21:1695-8.

[24] Doroodian A, Dengler JE, Genest A, Rosch N, Rieger B. Methylguanidinium borohydride: an ionic-liquid-based hydrogen-storage material. Angew Chem Int Ed Engl 2010;49: 1871-3.

[25] Wright WRH, Berkeley ER, Alden LR, Baker RT, Sneddon LG. Transition metal catalysed ammonia-borane dehydrogenation in ionic liquids. Chem Commun 2011;47:3177-9.

[26] Sutton AD, Burrell AK, Dixon DA, Garner EB, Gordon JC, Nakagawa $\mathrm{T}$, et al. Regeneration of ammonia borane spent fuel by direct reaction with hydrazine and liquid ammonia. Science 2011;331:1426-9.

[27] Scholten JD, Ebeling G, Dupont J. On the involvement of NHC carbenes in catalytic reactions by iridium complexes, nanoparticle and bulk metal dispersed in imidazolium ionic liquids. Dalton Trans 2007:5554-60.

[28] Neto BAD, Santos LS, Nachtigall FM, Eberlin MN, Dupont J. On the species involved in the vaporization of imidazolium ionic liquids in a steam-distillation-like process. Angew Chem Int Ed Engl 2006;45:7251-4.

[29] Csihony S, Fischmeister C, Bruneau C, Horvath IT, Dixneuf PH. First ring-opening metathesis polymerization in an ionic liquid. Efficient recycling of a catalyst generated from a cationic ruthenium allenylidene complex. New J Chem 2002;26:1667-70.

[30] Jessop PG, Jessop DA, Fu DB, Phan L. Solvatochromic parameters for solvents of interest in green chemistry. Green Chem 2012;14:1245-59. 